\title{
ELECTROHYDRODYNAMIC ATOMISATION OF WATER STABILISED BY GLOW DISCHARGE - OPEARTING RANGE AND DROPLET PROPERTIES
}

\author{
Borra J-P ${ }^{+}$, Ehouarn P, Boulaud D * \\ Laboratoire de Physique des Gaz et des Plasmas (CNRS), Equipe Décharges Electriques et Environnement, \\ Ecole Supérieure d'Electricité, Plateau de Moulon, 3 rue Joliot Curie, 91192 Gif-sur-Yvette Cedex, France \\ ( ${ }^{+}$Author to whom correspondence should be sent : jp.borra@pgp.u-psud.fr) \\ * Institut de Radioprotection et de Sûreté Nucléaire, Saclay, Bât. 389, 91192 Gif-sur-Yvette, France
}

\begin{abstract}
:
This paper deals with the production of charged water droplets by ElectroHydroDynamic Atomisation (EHDA) of water, in air at atmospheric pressure, in a mode stabilised by a particular corona discharge regime. Indeed, impulse filamentary discharges developing in the gas around the liquid cone temporarily disrupt the EHD equilibrium leading to an unstable mode of EHDA with varying droplet properties (size and charge). The purpose of this paper is to show that a stable mode can be obtained by the control of the field divergence around the liquid, i.e. the electric field profile in the gas, leading to a continuous glow discharge without impulse filamentary discharge. Using observations, electrical measurements and droplets size characterisation, several spraying modes are depicted. We have demonstrated that the electrical discharge regime (continuous/impulse) induces the mode of EHDA (stable/unstable). The stability domains are defined versus liquid flow rate, conductivity, voltage for different nozzle diameters. Then, the properties of droplets (droplets diameter, spray current) produced within these modes are established as a function of the liquid flow rate, of the conductivity and of the glow current.
\end{abstract}

\section{INTRODUCTION}

The objective of this work is to develop a system for the filtration of particulate pollution, based on electrostatic coagulation between pollutant particles and collector droplets (Ehouarn, 2001). In order to control the properties of the collector droplets, a production device of electrically charged micrometer water droplets by ElectroHydroDynamic Atomisation (EHDA) is studied. The main interest of this electro-spray production device for electrostatic coagulation, lies on the strong electric charge of droplets $(\sim 70 \%$ of the Rayleigh charge limit), higher than those reached by other production devices (Bailey, 1988 ; Cloupeau and Prunet-Foch, 1989 ; Michelson, 1990). Moreover the properties of charged water droplets (electrical mobility and massic charge) can be controlled through regulation parameters such as the liquid flow rate and the conductivity.

This spraying process is generally observed by applying a voltage difference of several thousand volts between a plane and a nozzle through which a liquid flows (Zeleny, 1915 ; Vonnegut and Neubauer, 1952 ; Taylor, 1964). By increasing this potential, different modes of droplet production are defined. A mode called "cone-jet mode" shows the advantage of producing strongly charged micrometer droplets with narrow size and charge distributions (stable production). While some authors define this "cone-jet mode" by the geometry of the liquid in a conical shape ended by a jet at its tip (Cloupeau and Prunet-Foch, 1989, 1990 ; Grace and Marijnissen, 1994), others define it from a relation between droplet properties (spray current, droplet diameter) and experimental parameters (liquid flow rate, conductivity) based on electrohydrodynamic equilibrium considerations (Fernandez de la Mora and Loscertales, 1994 ; Ganan-Calvo, 1997 ; Hartman, 1998).

The principle of the atomisation in this stable cone-jet mode is the following : when an electric field is applied, positive and negative charges separate inside the liquid and charges of the same polarity than the nozzle move towards the drop surface, inducing a surface charge density. Thus, the electrostatic pressure, induced at the liquid surface, increases against the 
capillarity pressure, and the shape of the drop surface changes into a cone. The tangential electric field in this cone accelerates the charges at the liquid surface toward the cone apex, from which a jet emerges, breaking up into droplets due to hydrodynamic instabilities propagation. Two types of processes are involved : an electrohydrodynamic process for the liquid cone and jet formation (EHD equilibrium), and a hydrodynamic process for the jet break-up. In this cone-jet mode, several laws have been established to calculate the droplets properties which depend on experimental parameters, such as the liquid flow rate $\mathrm{Q}_{\text {liq }}(\mathrm{ml} / \mathrm{h})$, the conductivity $\lambda(\mathrm{S} / \mathrm{m})$, the density $\rho\left(\mathrm{kg} / \mathrm{m}^{3}\right)$, the viscosity $\eta(\mathrm{Pa} . \mathrm{s})$, the surface tension $\gamma$ $(\mathrm{N} / \mathrm{m})$ and the relative permittivity $\varepsilon$ (Fernandez de la Mora and Loscertales, 1994 ; GananCalvo et al., 1997 ; Hartman, 1998).

However, if the threshold field of gas ionisation is reached before the threshold field of cone-jet mode (required for the EHD equilibrium), electrical discharges can prevent the establishment of this mode. Some authors observe that an increased surface tension leads to an increased threshold voltage of the cone-jet mode (Burayev and Vereshchagin, 1972 ; Smith, 1986 ; Hartman, 1998 ; Borra et al., 1999 ; Ehouarn, 2001). For liquid with high surface tension (e.g. for water $\gamma=0.072 \mathrm{~N} / \mathrm{m}$ ), the establishment of stable sprays is usually prevented by impulse filamentary discharges developed in the air around the liquid (Hayati et al., 1987 ; Cloupeau, 1994 ; Borra et al., 1996 ; Jaworek and Krupa, 1997). Some means to induce the stable mode of water EHDA have already been used such as (i) to increase the gas pressure, (ii) to use more insulating gases (e.g. $\mathrm{SF}_{6}, \mathrm{CO}_{2}$; Tang and Gomez, 1994, 1995), or (iii) to work with very fine nozzles $(<50 \mu \mathrm{m}$, Lopez-Herrera et al., 2002) to reduce the length of ionisation around the cone to such an extent that no more significant avalanches could lead to impulse filamentary discharge.

Up to now, EHDA of water coexisting with electrical discharges in air at atmospheric pressure, was unstable. The purpose of this article is first to depict the influence of electrical discharges regime on the production mode of water droplets EHDA by electric and size distribution measurements. From this correlation between the (impulse/continuous) discharge regimes and the related (stable/unstable) spraying modes, the physical conditions required to establish a stable mode of EHDA through the control of the field divergence around the liquid to promote a continuous glow discharge without impulse filamentary discharge are defined. Then, the operating ranges of this mode of EHDA stabilised by a continuous glow discharge are defined as a function of experimental parameters (liquid flow rate, voltage, conductivity for different nozzle diameters). Finally, the droplets properties (diameter and electric charge) are measured and calculated in order to establish empirical laws. 


\subsection{Experimental set-up}

\section{EXPERIMENTAL SET-UP AND DATA PROCESSING}

Fig. 1 shows the experimental configuration, in air at atmospheric pressure.

Production system

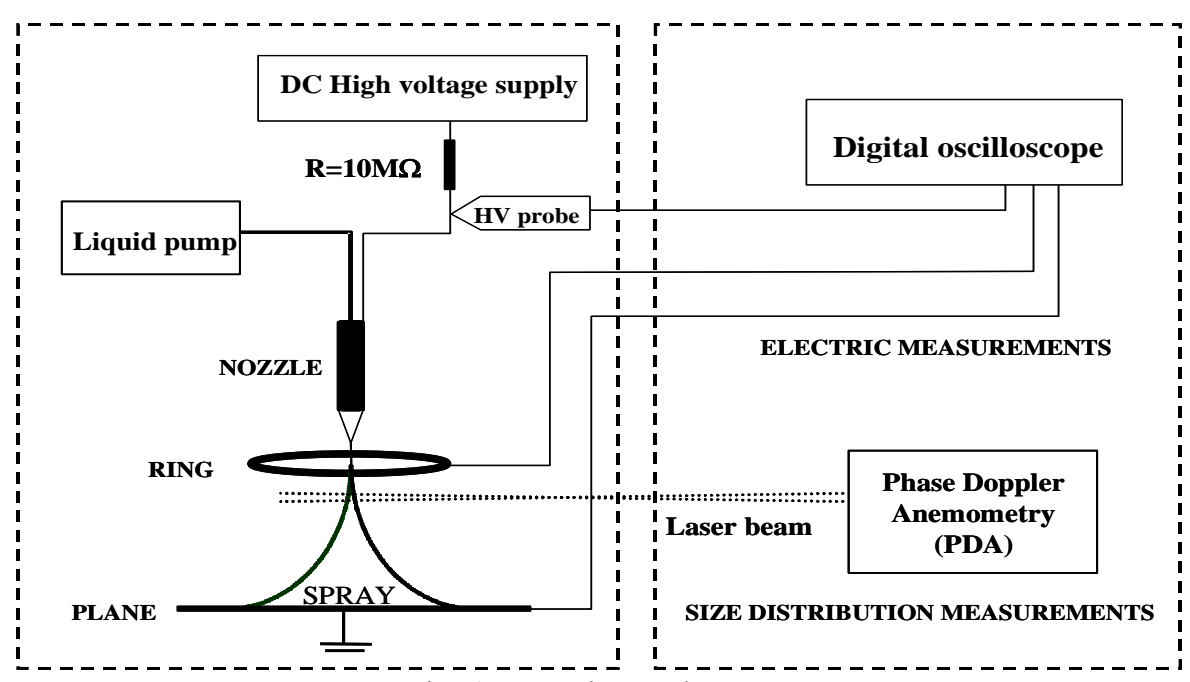

Fig. 1 Experimental system

The experimental configuration consists of a spraying nozzle supplied with DC voltage $(\mathrm{V}=0$ to $30 \mathrm{kV}$ ), and grounded electrode (plane and/or ring) perpendicular to the nozzle axis. The distance between the nozzle tip and the grounded electrode $d_{\text {gap }}$ is changed from 0.2 to $10 \mathrm{~cm}$. A high voltage probe monitors the nozzle voltage. All the results presented here are obtained under positive polarity, but the results are similar under negative polarity. The outlet diameter of the metallic nozzles $\mathrm{D}_{\text {out }}$ lie from 8.0 to $0.5 \mathrm{~mm}$. The smallest nozzle diameters are limited to avoid the risk of nozzle occlusion and to have a good mechanical rigidity. The nozzle is fed with water $(\gamma=0.072 \mathrm{~N} / \mathrm{m})$ which conductivity lies between 40 to $10000 \mu \mathrm{S} / \mathrm{m}$. The liquid flow rate can be adjusted between 0.1 and $200 \mathrm{ml} / \mathrm{h}$ (from $2.7 .10^{-11}$ to $5.5 .10^{8}$ $\mathrm{m}^{3} / \mathrm{s}$ ) by a liquid pump. Without liquid polarisation $(\mathrm{V}=0 \mathrm{kV})$, the pendent drops simply drip from the nozzle over the entire flow rate range of interest.

\subsection{Measurements}

Different diagnostic techniques are used to monitor the spraying modes :

Observations : the liquid cone and jet shape are visible. Transient disruption of the EHD equilibrium and the resulting modifications of the shape and of the position of the soproduced cloud of charged droplets are characterised by observations of back-scattered white light on the water droplets. Moreover, to locate the electrical discharges from their characteristic blue-violet light emission from the ionisation volume, photographs are taken in the dark with a time exposure of $60 \mathrm{~s}$ (ex : Fig.4.a).

Size distributions measurements : the droplet diameter (from 1 to $480 \mu \mathrm{m}$ ) is measured by scattering of interference fringes arising from the crossing of two laser beams on particles (technique based on Doppler effect). The measurements are made at $2 \mathrm{~mm}$ from the jet fragmentation zone in the centre of the spray (ex : Fig.9).

Electric measurements : the electric current collected at the grounded plane is measured by an oscilloscope (bandwidth $=200 \mathrm{MHz}$ ) allowing to differentiate the different current components (ex: Fig.2): (i) impulse current related to filamentary discharges, with characteristic transit time around $200 \mathrm{~ns}$; (ii) current due to consecutive millimetre sized 
droplets with characteristic transit time around $5-10 \mathrm{~ms}$; (iii) a continuous current due to the transport of different charged species in the gap : micrometer droplets from the EHDA (spray current) and gaseous ions produced by glow discharge (glow current). To separate these two continuous currents, grounded rings can be placed a few millimetres from the tip of the jet (cf. § 3.3.2 and Fig.11).

$0.3 \mu \mathrm{A} \& 5 \mathrm{~ms} /$ division

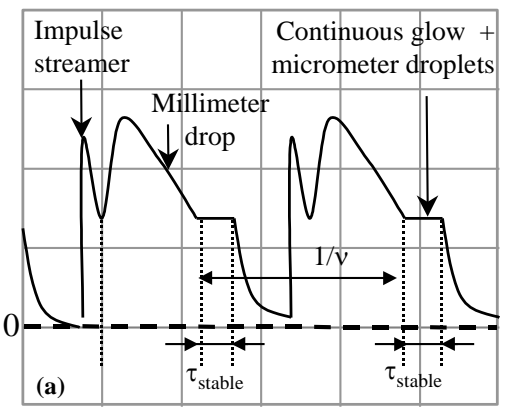

$0.6 \mu \mathrm{A} \& 5 \mathrm{~ms} /$ division

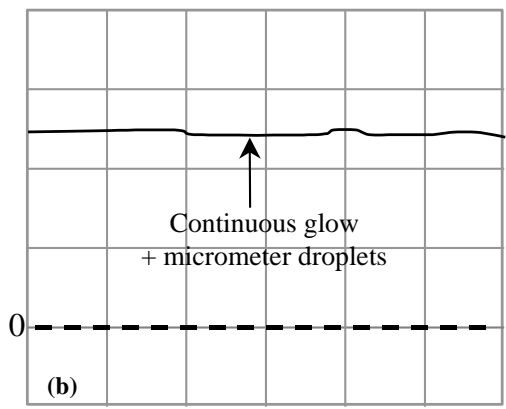

$1 \mu \mathrm{A} \& 1 \mathrm{~ms} /$ division

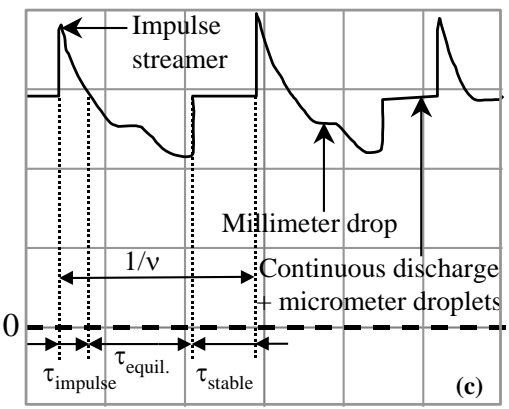

Fig. 2 Oscilloscope records in the unstable electric-dripping mode [(a) V=7 kV ; (c) V=20 kV] and in the mode stabilised by a glow discharge $[(\mathrm{b}) \mathrm{V}=16 \mathrm{kV}]$

(Nozzle-to-plane configuration, $d_{\text {gap }}=4 \mathrm{~cm}, D_{\text {out }}=1.8 \mathrm{~mm}, D_{\text {in }}=0.2 \mathrm{~mm}, \lambda=100 \mu \mathrm{S} / \mathrm{m}, \mathrm{Q}_{\text {liq }}=200 \mathrm{ml} / \mathrm{h}$ )

\subsection{Data treatment}

We define the EHDA modes from observations and photographs as well as from size distribution and current measurements. The mode is considered as "stable" when the micrometer droplets properties measured in the centre of the spray just below the production zone at the tip of the jet, are constant and the size distribution is unimodal, such as in the standard cone-jet mode without discharge. The mode is considered as "unstable" when the micrometer droplets properties are variable and the size distribution is polymodal such as the "spindle", the "intermittent cone-jet", the "ramified-jet" modes (described by Cloupeau and Prunet-Foch, 1990), as well as the "precession", the "oscillating-jet" and the "multi-spindle" modes (described by Jaworek and Krupa, 1997). From an electrical point of view, the stable mode of EHD Atomisation is characterised by a continuous current (ex : Fig.2). Indeed, using oscilloscope records, we define the probability to spray in this stable mode $\left(P_{\text {stable }}\right)$ by its duration $\left(\tau_{\text {stable }}\right)$ times its frequency : $P_{\text {stable }}=v \tau_{\text {stable. }}$. As an example, the Fig. 3 shows this probability measured versus the liquid flow rate for different voltages on the bigger nozzle which is shown not to enable the EHDA of water at atmospheric pressure in air in the mode stabilised by a continuous glow discharge. Indeed, the EHDA is considered as stable for a probability equal to one and as unstable for a lower probability.

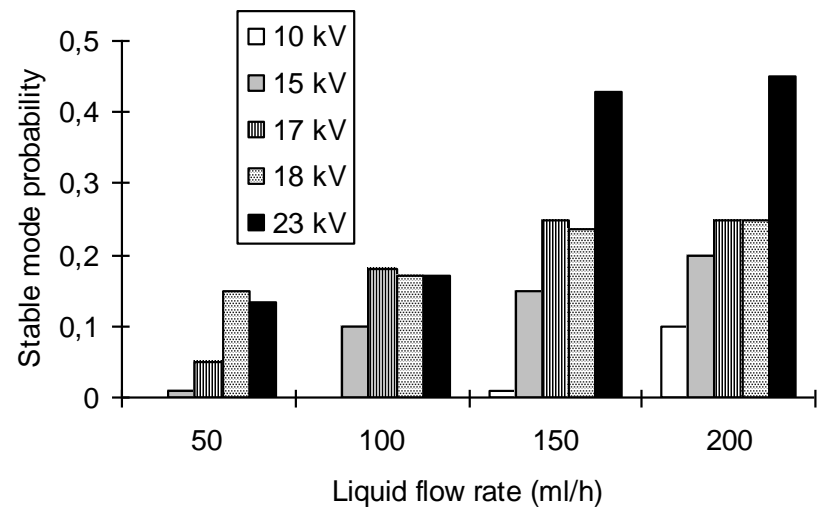

Fig. 3 Stable mode probability as a function of liquid flow rate for different voltages (Nozzle-to-plane configuration, $\mathrm{d}_{\text {gap }}=7.5 \mathrm{~cm}, \mathrm{D}_{\text {out }}=8.0 \mathrm{~mm}, \mathrm{D}_{\text {in }}=0.3 \mathrm{~mm}, \lambda=40 \mu \mathrm{S} / \mathrm{m}$ ) 


\section{RESULTS AND DISCUSSIONS \\ 3.1. Electrical discharge regimes and modes of EHD Atomisation}

A nozzle-to-plane configuration of EHDA is used to control the electric field profiles in the inter-electrode gap (dissymmetry of electrodes and strong heterogeneity of the electric field) close to the reference point-to-plane configuration used for electrical discharge study (Hartmann et al., 1963). The aim of this paragraph is to show the influence of electrical discharge regimes on the stability of EHDA modes at constant liquid flow rate and conductivity. In others terms, we intend to demonstrate that the electric field required at the liquid surface to reach EHD equilibrium is controlled by the voltage and the resulting (constant/transient) densities of gaseous discharge ions related to the (continuous/impulse) electrical discharge regime.

Fig. 4.a shows the current-voltage characteristic of a water spray. Photographs are taken in the dark (exposure time of $60 \mathrm{~s}$ ) to locate the electrical discharges in the gas around the liquid cone. Fig. 4.b presents the impulse frequency $v_{\text {impulse }}(\mathrm{Hz})$ and the electric charge per impulse discharge $\mathrm{Q}_{\text {impulse }}(\mathrm{C})$ as a function of voltage. In the same way, Fig. 4.c shows the probability of the stable mode $\mathrm{P}_{\text {stable }}$ as a function of voltage. The experiment is carried out with a liquid flow rate of $100 \mathrm{ml} / \mathrm{h}$ and water conductivity of $100 \mu \mathrm{S} / \mathrm{m}$, in the nozzle-to-plane configuration. The results are shown in term of voltage, correlated to the electric field, allowing to compare the results for the same experimental conditions (nozzle and grounded electrodes geometry, gap distance).

From Fig. 4, the liquid flow rate and the conductivity being constant, four zones are distinguished when the voltage increases, in relation with four modes of EHDA :

At $\mathrm{V}=0 \mathrm{kV}$, without liquid polarisation, the pendent drops simply drip from the nozzle.

From $\mathrm{O}$ to $2 \mathrm{kV}$ (Fig.4, zone 1), the current increases (below $1 \mathrm{nA}$ ), with the droplets production frequency $\left(v_{\text {droplets }}=0-100 \mathrm{~Hz}\right)$ and with the electric charge per droplet $\left(\mathrm{q}_{\text {droplet }}\right)$ without any impulse filamentary discharge $\left(I=q_{\text {droplet }} v_{\text {droplets }}\right)$. The electric field at the liquid surface is lower than the field required for EHD equilibrium and the resulting field in the gas is lower than the threshold field of gas ionisation. The stable mode probability is equal to zero. The dripping mode is established, leading to millimetre sized droplets.

From 2 to $11.4 \mathrm{kV}$ (Fig.4, zone 2), small impulse electrical discharges are superposed on the droplets current component. The average current increases from 1 to $1.8 \mu \mathrm{A}$ $\left(\mathrm{I}=\mathrm{q}_{\text {droplet }} v_{\text {droplet }}+\mathrm{q}_{\text {impulse }} v_{\text {impulse }}\right)$, with the impulse frequency and the amount of electric charge per impulse ( $v_{\text {impulse }}=0-15 \mathrm{~Hz}$ and $\mathrm{q}_{\text {impulse }}=1-100 \mathrm{pC}$ ), as well as with the droplet frequency varying in the range $\left[100-10^{6} \mathrm{~Hz}\right]$. These parameters are characteristic of a pre onset-streamer impulse regime (Hartmann et al., 1963 ; Nasser, 1971). The periodic succession of impulse discharge, millimetre drop emission and stable EHDA of fine water droplet mist, (ex : Fig. 2.a) can be explained as follow. Indeed, in this voltage range, when the drop grows at the tip of the nozzle, the resulting field in the gas around the liquid overcomes the threshold field of gas ionisation and impulse electrical discharges appear. The space charge field induced by gaseous ions created by these discharges, temporarily decreases the field in the gas around the liquid, preventing from new electrical impulse development during the millimetre drop emission followed by the stable EHDA of fine water droplet mist for a few milliseconds. This EHD equilibrium is disrupted because the field at the liquid becomes smaller than the threshold field of EHDA due to space charge field created by the charged water droplets so that the cone turns to a pendant drop shape. When the space charge is collected on grounded 
electrode, the field in the gas around the liquid comes back to its original value before ionisation, allowing, once again, gas ionisation measured as impulse currents.

In this voltage range, the variation of the electric field at the liquid surface, induced by the transient flux of gaseous ions, is low compared to the geometric field : the stable mode probability increases with voltage in spite of small impulse discharges (see Fig 4.c). This electric-dripping mode of EHDA is established, leading to polymodal sub-millimetre sized droplets (ex : Fig.9.a).

(a)

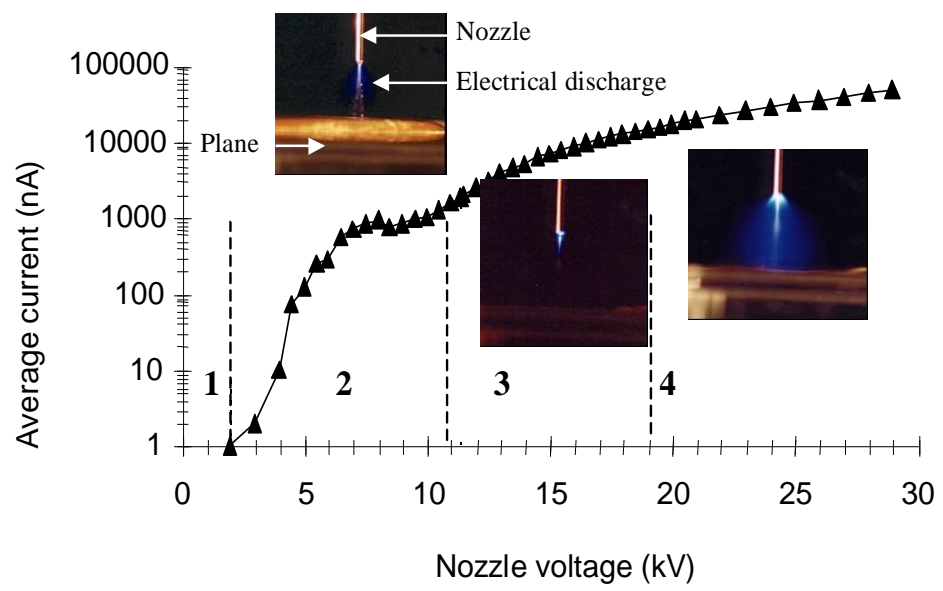

(b)

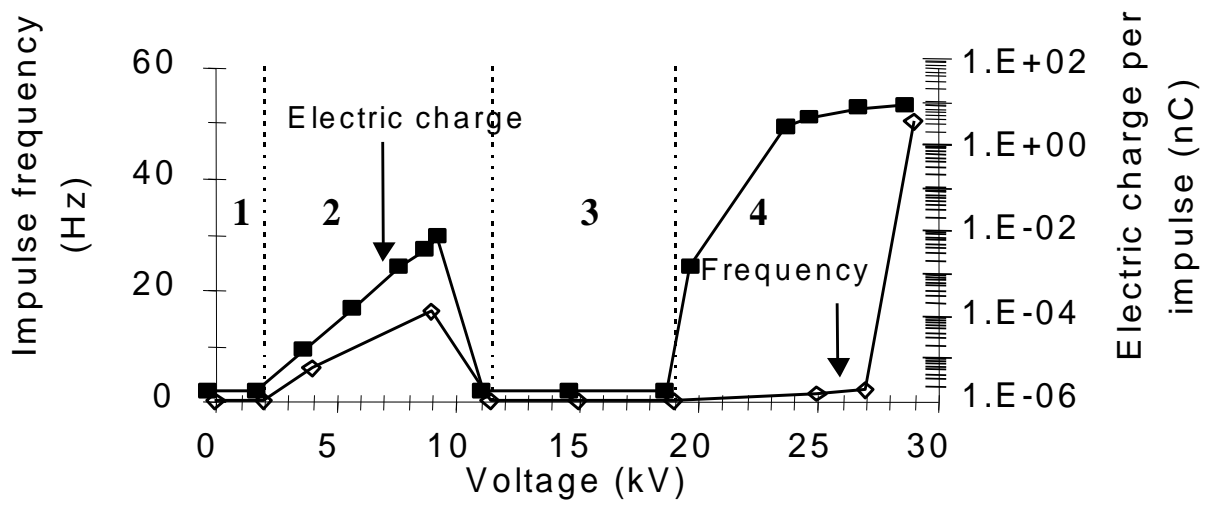

(c)

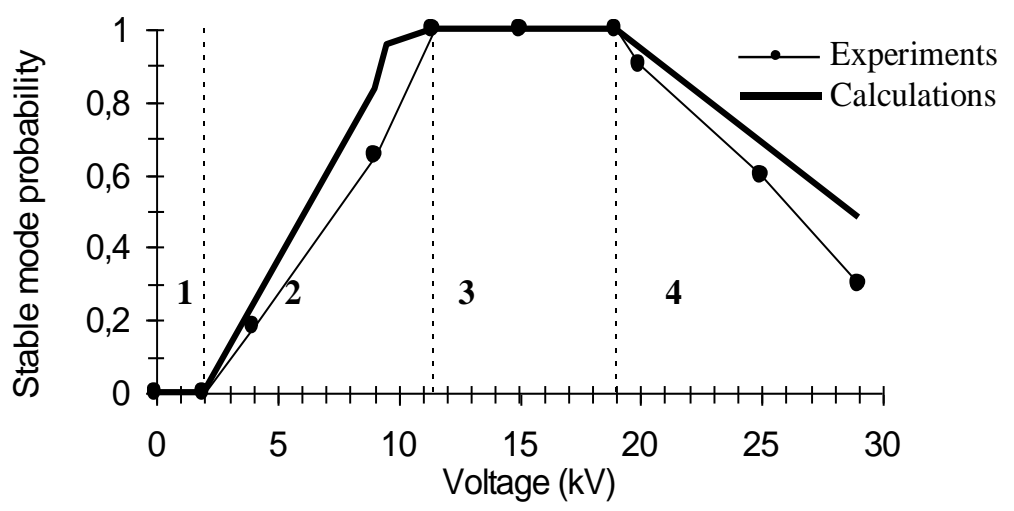

Fig. 4 (a) Current-voltage characteristic [photographs taken in the dark : exposure of $60 \mathrm{~s}$ ]

(b) Impulse frequency and amount electric charge per impulse,

(c) probability of the mode stabilised by a glow discharge, as a function of the nozzle voltage

(Nozzle-to-plane configuration, $\mathrm{d}_{\mathrm{gap}}=4 \mathrm{~cm}, \lambda=100 \mu \mathrm{S} / \mathrm{m}, \mathrm{Q}_{\text {liq }}=100 \mathrm{ml} / \mathrm{h}$ ) 
From 11.4 to $19 \mathrm{kV}$ (Fig.4, zone 3), the average current increases from 1.8 to $15.1 \mu \mathrm{A}$; the impulse frequency and the amount of electric charge per impulse are equal to $0:$ a continuous glow discharge is established in the high field volume around the liquid cone (see picture 3 on Fig 4.a). The space charge field created by gaseous ions is now preponderant over the geometric field and controls the field at the liquid surface and in the gas (lower than the critical field of streamer propagation further from the corona ionisation zone located close to the liquid surface), preventing thus the formation of impulse discharges. The constant charge density resulting from this continuous ionisation in glow regime leads to a constant electric field at the liquid surface and stabilise the EHD equilibrium and so the atomisation (ex : oscilloscope record: Fig.2.b) : the stable mode probability is equal to 1 . The current increases with the voltage because of the glow intensification (evaluated from light emitted from the glow and ring current measurements). The mode stabilised by a continuous glow corona discharge is established, leading to unimodal micrometer sized droplets (ex : Fig.9.b).

Above $19 \mathrm{kV}$ (Fig.4, zone 4), the average current increases from 15.1 to $47.2 \mu \mathrm{A}$, with the frequency of impulse filamentary discharges and with the amount of electric charge per impulse $\left(v_{\text {impulse }}=0-50 \mathrm{~Hz}\right.$ and $\left.\mathrm{Q}_{\text {impulse }}=0.2-10 \mathrm{nC}\right)$. These parameters are characteristic of the streamer regime. The space charge field created by the gaseous ions temporally (i) reduces the electric field at the liquid surface and (ii) increases the field between the space charge and the plane up to the critical field of streamer propagation in the gap (Meek, 1940 ; Raether, 1941), so that filamentary streamers develop like a «brush» around the droplets spray. These transient gaseous ions flux in the gap perturbs the electric field at the liquid surface and temporarily disrupts the EHD equilibrium (ex : oscilloscope record : Fig.2.c) : the stable mode probability decreases with voltage. When an impulse discharge occurs, the liquid cone oscillates leading to unstable jets and to the production of polymodal millimetre and micrometer droplets (ex : Fig.9.c). An unstable electric-dripping mode is established.

From electric measurements, we have observed that in the nozzle-to-plane configuration, the increase of voltage leads to the same succession of electrical discharge regimes than in the metallic point-to-plane configuration. Nevertheless, some differences exist between these two configurations : as shown on photographs in Fig. 4.a, the discharges can be located by the emitted light (white dotted lines). In the standard metallic point-to-plane configuration, the ionisation zone (defined by the length where the field in the gas is higher than the ionisation threshold field, cf. §3.2.1) is located at the tip of the point; in the nozzle/liquid-to-plane configuration, this zone spreads over the liquid cone and jet as well as on the nozzle edges for higher voltage. Then, the density of positive charged droplets induces a modification of the spatial development of impulse discharge. The pictures taken in the dark. Fig.4.a, zone 4, confirms the creation of filamentary discharges (streamers) and their propagation in the gap like a «brush» around the droplets spray. Then, the positive gaseous ions created by discharges in the gas around the liquid, are repelled from the positive cloud of droplets.

From electric measurements (Fig.2 and Fig.4), it seems that a strong impulse current induces a variable electric field at the liquid surface which disturbs the EHDA process whereas a continuous current promotes a stable EHDA. This assumption is right if it exists a correlation of impulse frequency and intensity with the destabilisation duration of EHDA :

$$
P_{\text {stable }} \sim 1-\left[\left(v_{\text {impulse }} \times \tau_{\text {equilibrium }}\right) \times\left(K^{\prime} \frac{Q_{\text {impulse }}}{Q_{\text {continuous }}}\right)^{K}\right]
$$




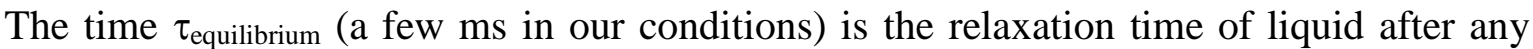
perturbation resulting, in that case, from the electric field perturbation induced by the transient flux of gaseous ions measured as impulse discharge. The term $\mathrm{Q}_{\text {impulse }} / \mathrm{Q}_{\text {continuous }}$ is included to take into account the relative importance between the intensity of the transient space charge field variation (related to the amount of electric charge per pulse) and the constant space charge field related to the amount of electric charge corresponding to the continuous current component during the pulse $\left(\mathrm{Q}_{\text {continuous }}=\mathrm{Q}_{\text {glow }}+\mathrm{Q}_{\text {spray }}\right)$ : the gaseous ions density created by impulse discharges can be low compared to the constant space charge density related to continuous fluxes of charged droplets and corona glow ions $\left(\mathrm{Q}_{\text {impulse }}<<\mathrm{Q}_{\text {continuous }}\right)$; in that case, filamentary impulse discharges do not perturb neither the electric field at the liquid surface nor the EHD equilibrium (ex : zone 2). K and $\mathrm{K}^{\text {' }}$ respectively (0.03 and 0.8$)$ are two constants which depend on the configuration.

From Fig.4.c, it can be seen that experimental results are in good agreement with this equation arising from theoretical considerations based on the mentioned assumptions. Thus, we confirm that the electrical discharge regime induces the EHDA mode and the resulting droplet properties. The electric field at the liquid surface is controlled by the space charge of gaseous ions produced by discharges. An impulse discharge (streamer) creates a transient increase of charge density in the gap leading to a relative transient decrease of the electric field at the liquid surface, which prevents or disrupts the EHD equilibrium required for the stable EHDA (electric-dripping mode). A continuous discharge (glow) creates a constant charge density around the liquid which leads to a constant electric field at the liquid surface, and allows to stabilise the EHDA process (mode stabilised by a glow discharge).

\subsection{Operating ranges}

\subsubsection{Physical conditions for the mode stabilised by a glow discharge}

Two physical conditions are required to induce the EHDA of liquids in the mode stabilised by a continuous glow discharge in air at atmospheric pressure : (i) the first condition is related to the electric field normal to the liquid surface $\left(E_{n}\right)$, which has to reach the threshold field $E_{n}$ EHDA required for the formation of the liquid cone due to EHD equilibrium (same condition than for the EHDA in the cone-jet mode without electrical discharge); (ii) the second condition is related to the electrical field in the gas to promote the continuous glow discharge regime to stabilise the spraying mode. The different electrical discharge regimes are defined according to the electric field intensity at the liquid surface and according to the length of ionisation L (m), which corresponds to the length where the field in the gas is higher than the threshold field of gas ionisation (Townsend, 1914). This length depends on the voltage and on the radius of curvature of the high field electrode (nozzle, liquid cone and jet), according to the resulting field divergence in the gap. Fig. 5 shows schematic examples of electric field profiles versus a curvilinear abscissa on an electric field line from the liquid surface (at $s=0$ ) to explain the regime of electric discharge which develops in the gas around the liquid in terms of electric field divergence in relation with the four successive modes of EHDA observed by increasing the voltage on Fig. 4 : 

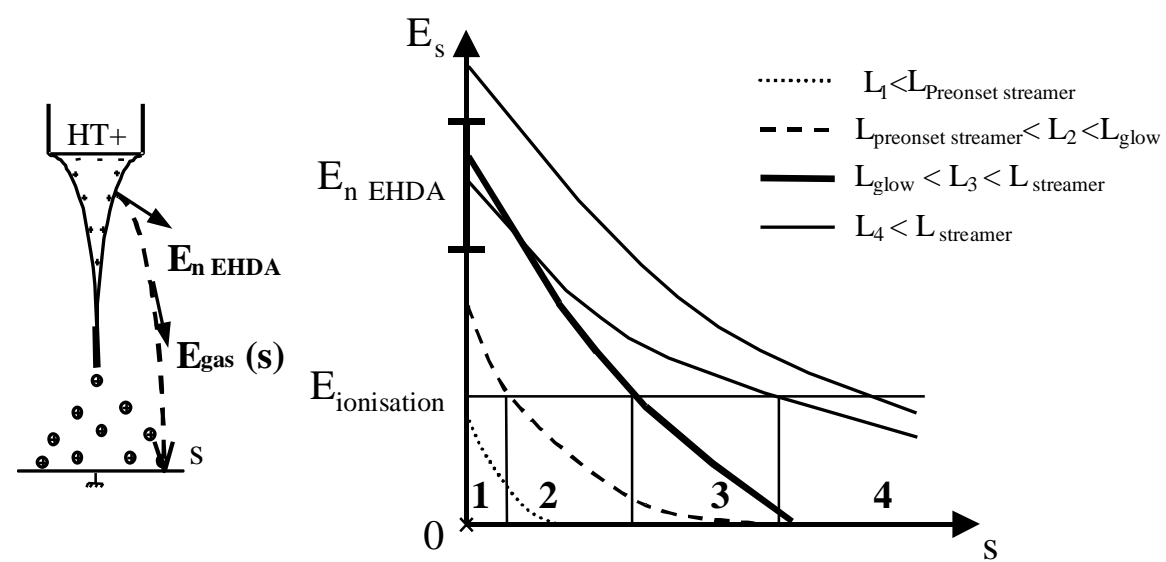

Fig. 5 Schematic examples of electric field profiles versus a curvilinear abscissa for the different electrical discharge regimes

When the electric field at the liquid surface is lower than the threshold field of gas ionisation:

Zone 1 : the dripping mode is established because the electric field normal to the liquid surface $\left(E_{n}\right)$ is lower than the threshold field $E_{n \text { EHDA }}$ for EHD equilibrium, preventing thus the cone and jet formation (see small dotted line on Fig. 5).

When the electric field at the liquid surface is higher than the threshold field of gas ionisation, the following cases can take place :

Zone 2: the unstable electric-dripping mode is established due to pre-onset streamer discharge and related transient surface field variations, disrupting the EHD equilibrium (see comments of Fig. 4). This occurs either when the electric field at the liquid surface is lower than the threshold field $\mathrm{E}_{\mathrm{n} \text { EHDA }}$ and/or when the field divergence is strong (small nozzle diameter), leading to lengths of ionisation shorter than $\mathrm{L}_{\text {glow }}$, and higher than

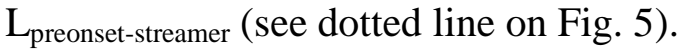

Zone 3 : the stable mode is established with a continuous glow discharge when the surface electric field is higher than the threshold field $\mathrm{E}_{\mathrm{n} \text { EHDA }}$ and when the field divergence leads to a length of ionisation included in the range between $\mathrm{L}_{\text {glow }}$ and $\mathrm{L}_{\text {streamer }}$ (see bold line on Fig. 5).

Zone 4: the unstable electric-dripping mode is established again when the electric field at the liquid surface is higher than the field $E_{n}$ EHDA and/or when the field divergence is too low to induce a glow discharge because of lengths of ionisation longer than $\mathrm{L}_{\text {streamer }}$ leading to impulse discharge and transient surface field variations disrupting the EHD equilibrium (see comments of Fig. 4 and full lines on Fig. 5).

As the physical process of disruption of EHD equilibrium by impulse discharges seems to be understood, we took into account Hartmann's experiment showing that the continuous glow regime of electrical discharges is favoured by highly diverging field promoted with smaller radius of curvature in classical point-to-plane discharge geometry (1963). The aim is now to define the functioning conditions inducing such highly diverging fields required for EHDA in this mode stabilised by a glow discharge, by controlling the electric fields $\left(\mathrm{E}_{\mathrm{n}}\right.$ and $\left.\mathrm{E}_{\mathrm{gas}}\right)$ versus experimental parameters $\left(\mathrm{D}_{\text {nozzle }}, \lambda\right)$ and regulation parameters $\left(\mathrm{V}, \mathrm{Q}_{\mathrm{liq}}\right)$. 


\subsubsection{Influence of nozzle geometry on functioning voltage and liquid flow rate}

Fig. 6.a shows the voltage and liquid flow rate operating ranges for different nozzle diameters. In our experimental conditions ( $\mathrm{V} \leq 29 \mathrm{kV}, \mathrm{Q}_{\mathrm{liq}} \leq 200 \mathrm{ml} / \mathrm{h}, \lambda=100 \mu \mathrm{S} / \mathrm{m}$ ), it was not possible to atomise solutions when nozzles with diameters larger than $0.8 \mathrm{~mm}$ were used.

(a)

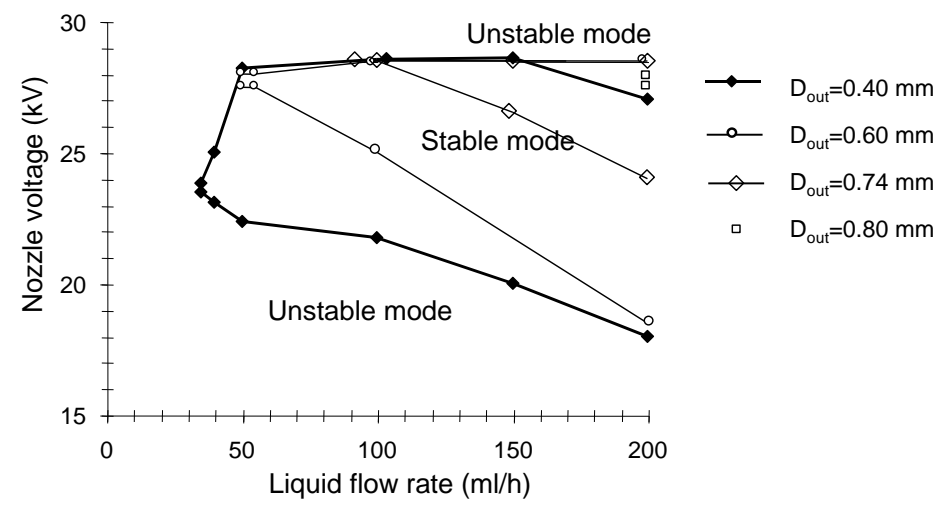

(b)

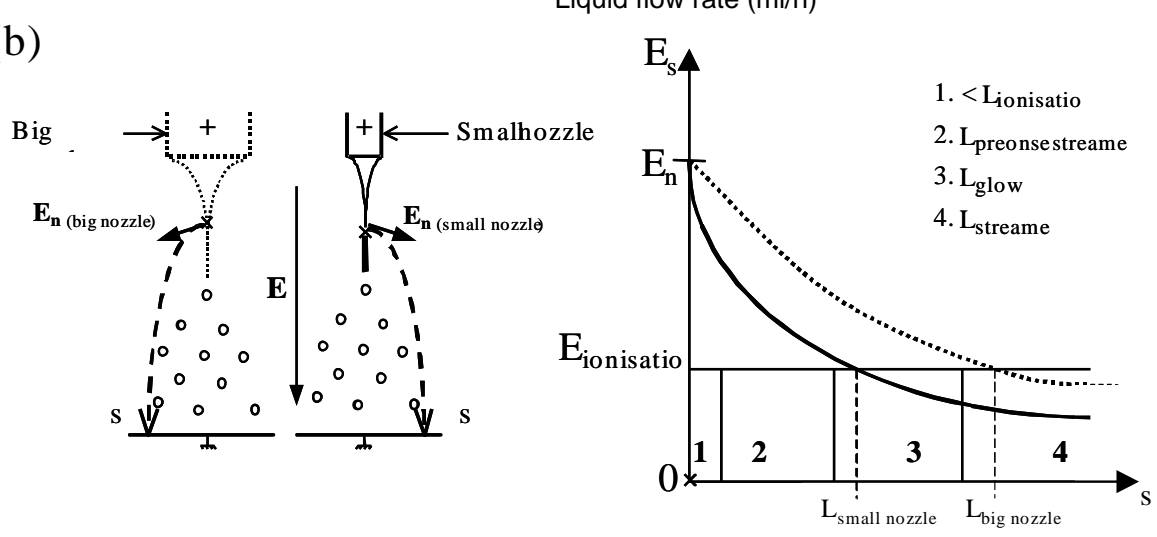

Fig. 6 (a) Operating ranges in the voltage-liquid flow rate space for different nozzle diameters (Nozzle-to-plane, $\mathrm{d}_{\mathrm{gap}}=4 \mathrm{~cm}, \lambda=100 \mu \mathrm{S} / \mathrm{m}$ ) (b) Profile of electric field for different nozzle diameters

First of all, whatever the nozzle diameter is, for constant conductivity and liquid flow rate, when the nozzle voltage increases, the (stable/unstable) modes are related to the (continuous glow / impulse streamer) discharge regimes.

In the mode stabilised by a glow discharge, as the droplets size has been shown not to be affected by the nozzle diameter, the jet diameter can be considered as identical for different nozzles. Assuming that the threshold field $\mathrm{E}_{\mathrm{n} \text { EHDA }}$ for EHD equilibrium is the same for any nozzle diameter (i.e. neglecting the modification of the gravity forces for different nozzle diameters), the ionisation length becomes shorter as the nozzle diameter is reduced: $\mathrm{L}_{\mathrm{big}}$ nozzle $>\mathrm{L}_{\text {small nozzle }}$ (see Fig. 6.b). Indeed, a reduction in the nozzle diameter increases the divergence of the electric field, promoting the continuous glow discharge regime (Hartmann et al., 1963) and the resulting stable mode for lower threshold voltage and on larger voltage range, instead of the impulse discharge regime and the resulting unstable electric-dripping mode (promoted by low diverging fields with big nozzles). In other words, the increase of the divergence of the electric field due to smaller nozzle diameter, reduces the impulse discharge probability which enables the EHDA of water in the mode stabilised by a glow discharge.

One can notes from Fig. 6.a, that the threshold voltage of the mode stabilised by a continuous glow discharge decreases for smaller nozzle diameters, whatever the flow rate is. Indeed, for similar voltage and flow rate, a smaller nozzle induces a thinner liquid cone leading to a higher electric field at the liquid surface. Thus, with smaller nozzles, the threshold field $\mathrm{E}_{\mathrm{n} \text { EHDA }}$ for EHD equilibrium is reached for lower voltages at any flow rate. 
Concerning the lower minimum liquid flow rate at constant voltage with smaller nozzles, this can be explained as follow. When the diameters of the nozzle and of the cone base decrease, the inward capillary pressure increases. To stabilise the EHDA by a glow discharge with smaller nozzles at a given voltage, the outward electrostatic pressure has to be increased by reducing the surface of the cone with lower liquid flow rates. Thus, with smaller nozzles, the threshold field $\mathrm{E}_{\mathrm{n}} \mathrm{EHDA}$ for EHD equilibrium is overcome down to lower minimum liquid flow rate at a given voltage.

Finally, nozzles with smaller diameters enable to work at lower threshold voltage and up to higher threshold voltage of the unstable electric dripping mode so that the mode stabilised by a glow exist on a larger voltage range with smaller nozzles for a given flow rate. As the maximum flow rate that could be imposed to the liquid was smaller than the maximum liquid flow rate of the stable mode, the range of liquid flow rate could not be discussed.

In practical terms, for a constant conductivity, nozzles with smaller diameters enable to work in air at atmospheric pressure with lower threshold voltage and on a larger voltage range at constant flow rate and with lower minimum liquid flow rate at constant voltage, for EHDA of water in the mode stabilised by a glow discharge.

\subsubsection{Influence of conductivity on the functioning voltage and liquid flow rate}

Fig. 7.a shows the voltage and liquid flow rate operating ranges for different conductivities. In our experimental conditions ( $\mathrm{V} \leq 29 \mathrm{kV}, \mathrm{Q}_{\mathrm{liq}} \leq 200 \mathrm{ml} / \mathrm{h}$ ), it was not possible to electrospray aqueous solution with conductivity higher than $5000 \mu \mathrm{S} / \mathrm{m}$.

First of all, whatever the conductivity is, for constant nozzle diameter and liquid flow rate, when the nozzle voltage increases, the (stable/unstable) modes are related to the (continuous glow / impulse streamer) discharge regimes.

(a)

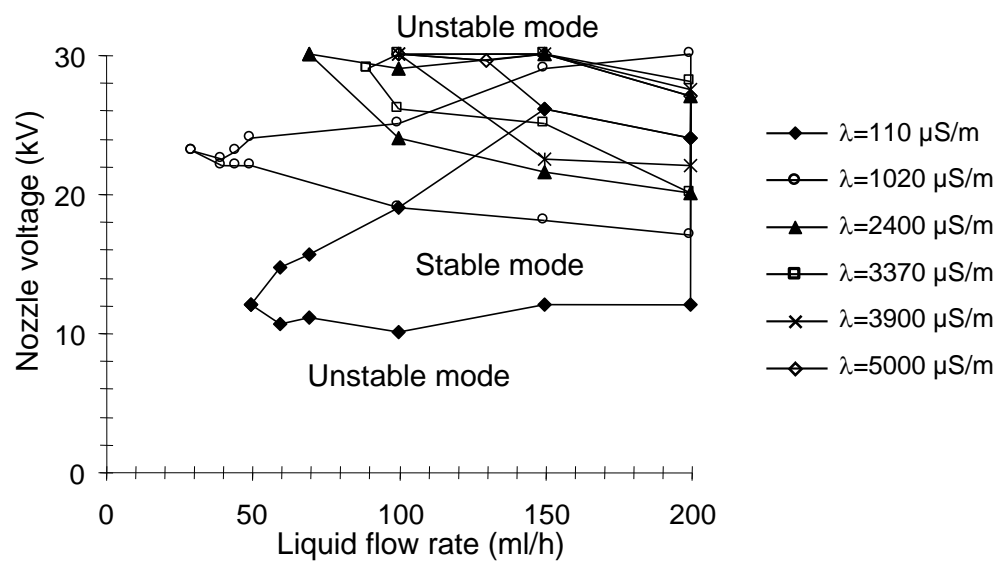

(b)
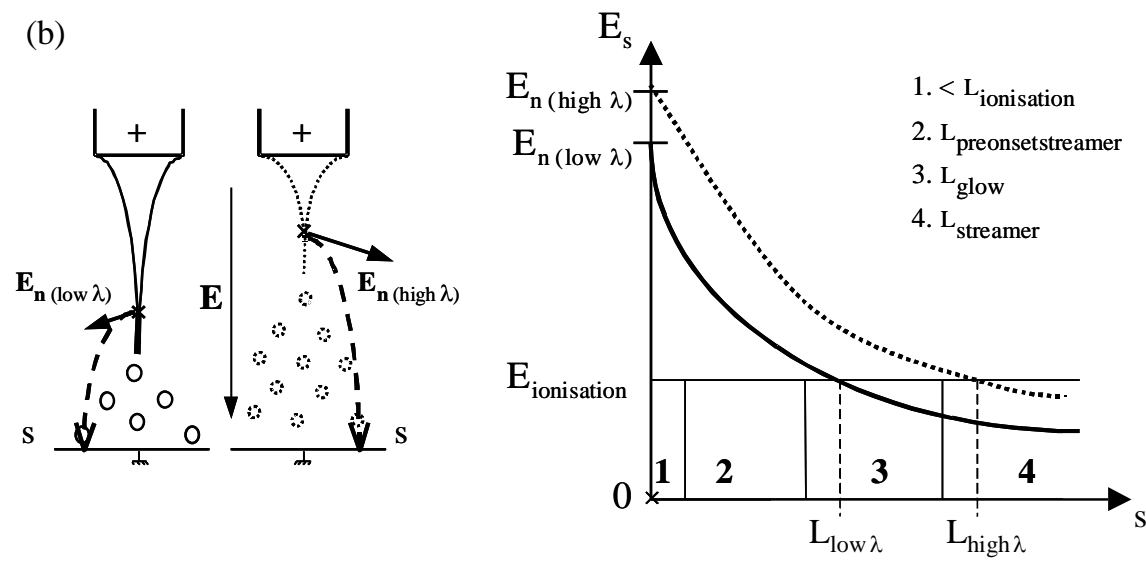

Fig. 7 (a) Operating ranges in the liquid flow rate-voltage space for different conductivities (Nozzle-to-plane configuration, $\mathrm{d}_{\text {gap }}=4 \mathrm{~cm}, \mathrm{D}_{\text {out }}=0.5 \mathrm{~mm}$ ) (b) Profile of electric field for different conductivities 
One can notes from Fig. 7.a, that the threshold voltage of the mode stabilised by a continuous glow discharge increases with the conductivity, whatever the flow rate is. This may be attributed to the development of impulse discharge from the nozzle edges with high conductivity liquid, whereas with reduced conductivities, the nozzle edges are less exposed to the field because of the liquid cone shape and discharges only occur around the liquid and not from the nozzle edges. Indeed, for increased conductivity, similar nozzle voltage induces an increase of outward electrostatic pressure so that, the inward capillary pressure must increase to balance the outward electrostatic pressure, as confirmed by the reduction of the cone volume (see Fig. 7b). Thus, the development of impulse discharge from the nozzle edges during EHDA of high conductivity liquid may offset the appearance of the glow alone, to higher voltages than with low conductivity liquid.

For conductivities lower than $1020 \mu \mathrm{S} / \mathrm{m}$, Fig. 7.a shows that when the conductivity increases, the minimum liquid flow rate required to establish the stable mode decreases, as in the standard cone-jet mode without discharge. Indeed, when the conductivity and the voltage increase, the electric field at the liquid surface increases ; the inward capillary pressure must be increased to balance the outward electrostatic pressure. Thus, the outward dynamic and hydrostatic pressures can be decreased to create smaller cone through lower liquid flow rate.

Nevertheless, for high conductivities $(\lambda>1000 \mu \mathrm{S} / \mathrm{m})$ and corresponding higher threshold voltages, the minimum liquid flow rate increases with conductivity. In fact, at a given flow rate, increased conductivities and voltage enhance the electrostatic pressure which overcomes the capillary pressure, preventing from cone formation by ejection of liquid directly from the nozzle in a multi-jet mode. Then, to reduce the electric field at the liquid surface, it is necessary to increase the dynamic pressure through the liquid flow rate in order to increase the cone volume and to stabilise the cone formation.

Fig. 7.a shows that the glow discharge stabilised EHDA mode is induced in a range of higher liquid flow rate $(35-200 \mathrm{ml} / \mathrm{h}$ ) and larger voltage (tens of $\mathrm{kV}$ ) than the classical conejet mode without discharge $(0.1-10 \mathrm{ml} / \mathrm{h}$ and a few $\mathrm{kV})$. This is important because it enables to extend the range of diameter and charge of water droplets that can be so-produced by EHDA stabilised by a glow (see $\S 3.3$ ).

\subsubsection{Electrode configurations}

Fig. 7.a shows the operating ranges in terms of voltage, conductivity and liquid flow rate, for the nozzle-to-plane configuration and Fig. 8, shows the same results in the nozzle-ring(s)to-plane configuration. Actually, this nozzle-ring(s)-to-plane configuration enables to induce a constant electric field at the liquid surface required for the stable production of droplet in different applications such as (i) the electrostatic coagulation (with variable net charge densities mixed under the ring) and/or such as (ii) Electro-spray coatings of insulated and thus polarised surfaces. 


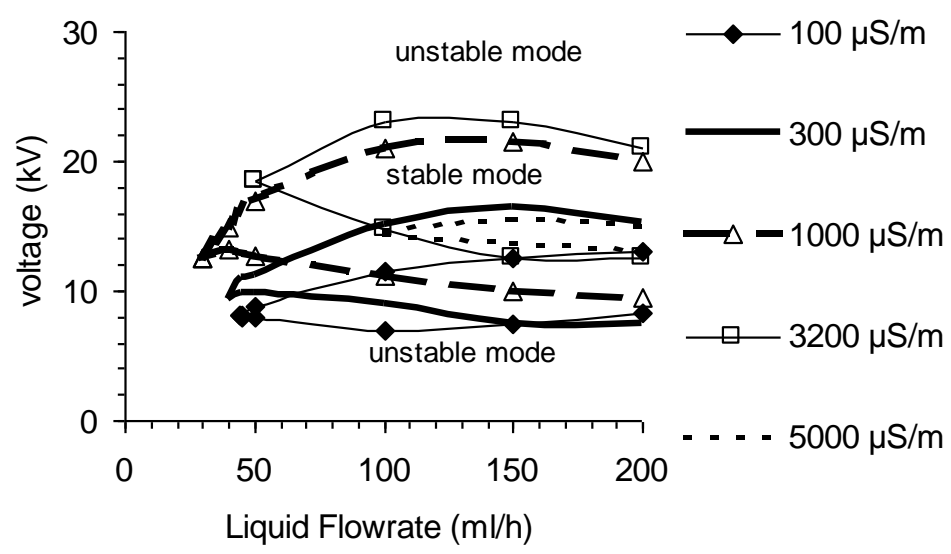

Fig. 8 : Operating ranges in the liquid flow rate-voltage space for different conductivities (Nozzle-ring-to-plane configuration, $\mathrm{d}_{\text {gap }}=4 \mathrm{~cm}, \mathrm{~d}_{\text {nozzle-ring }}=0.5 \mathrm{~cm}, \mathrm{D}_{\text {out }}=0.5 \mathrm{~mm}$ )

In nozzle-plane and nozzle-ring-plane configurations, we observe the same correlation between electrical discharge regimes and EHDA modes: an impulse discharge (streamer) leads to an unstable mode (electric-dripping) and a continuous discharge (glow) leads to a stable mode. However, in nozzle-ring-to-plane configuration, the gap between the electrodes is shorter, thus the domains of the stable EHDA are shifted to lower voltages. Then the spatial distribution of the droplets depends on the grounded electrode position which modifies the trajectory of the charged droplets (cf. § 3.3.2 and Fig.11).

\subsection{Droplets properties in the mode stabilised by a glow discharge}

\subsubsection{Droplets diameter}

Fig. 9 shows typical size distributions of water sprays at different voltages measured close to the fragmentation zone in the middle of the spray.

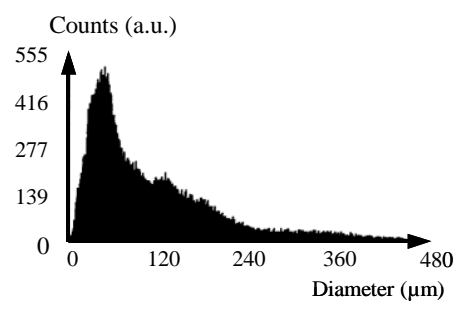

(a) Unstable electric-dripping $\operatorname{mode}(\mathrm{V}=10 \mathrm{kV})$

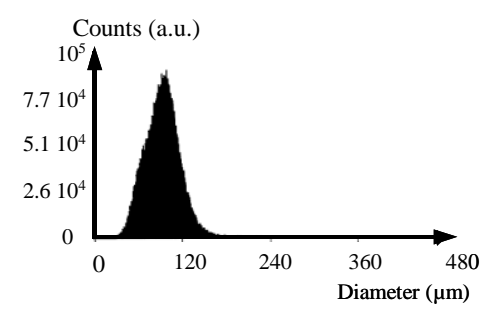

(b) Mode stabilised by glow discharge $(\mathrm{V}=16 \mathrm{kV})$

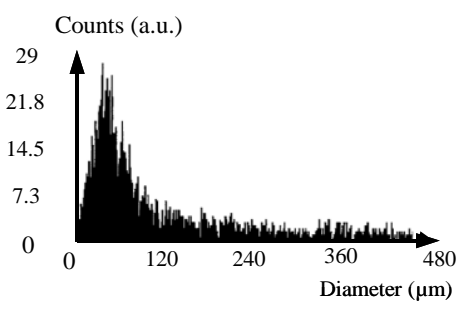

(c) Unstable electric-dripping mode $(V=27 \mathrm{kV})$

Fig. 9 Water droplet size distributions

(Nozzle-to-plane configuration, $\mathrm{d}_{\mathrm{gap}}=4 \mathrm{~cm}, \mathrm{D}_{\text {out }}=0.5 \mathrm{~mm}, \lambda=100 \mu \mathrm{S} / \mathrm{m}, \mathrm{Q}_{\mathrm{liq}}=100 \mathrm{ml} / \mathrm{h}$ )

With impulse streamer discharges (Fig.9.a and c), the unstable mode of EHDA leads to a polymodal size distribution caused by filamentary discharge development and by resulting transient variation of the surface electric field disrupting the EHD equilibrium.

With continuous glow discharge (Fig.9.b), the surface electric field is constant, the EHDA is characterised by an unimodal size distribution. When integrated over the spray surface, no satellites (as defined by Hartman 1998 by $\mathrm{d}_{\text {primary droplet }} / \mathrm{d}_{\text {satellites }} \sim 7-10$ ) are detected and only secondary droplets $\left(\mathrm{d}_{\text {primary droplet }} / \mathrm{d}_{\text {secondary droplet }} \sim 2\right)$ are present on the edge of the spray, leading to a relative standard deviation of the size distribution in the centre of the spray of 0.3 , far from monodisperse spray distribution obtained in the classical varicose cone jet mode with axi-symmetric fragmentation (relative standard deviation $<0.15$ ), but close to the typical polydispersion of spray distribution obtained in the kink asymmetric fragmentation mode (Hartman, 1998 and Camelot 2001). 
From experimental measurements (cf. Fig.10), it can be determined that the mean droplet diameter varies in this mode stabilised by a continuous glow discharge as :

$$
d_{\text {droplet }} \sim Q_{\text {liq }}{ }^{0.5} I_{\text {glow }}{ }^{-0.04} \lambda_{\text {liq }}{ }^{-0.2}
$$

The droplet diameter and the standard deviation increase with liquid flow rate as in the standard cone-jet mode without electrical discharge. When the liquid flow rate increases, the cone volume and the jet diameter increase, inducing a fragmentation of jet into bigger droplets.
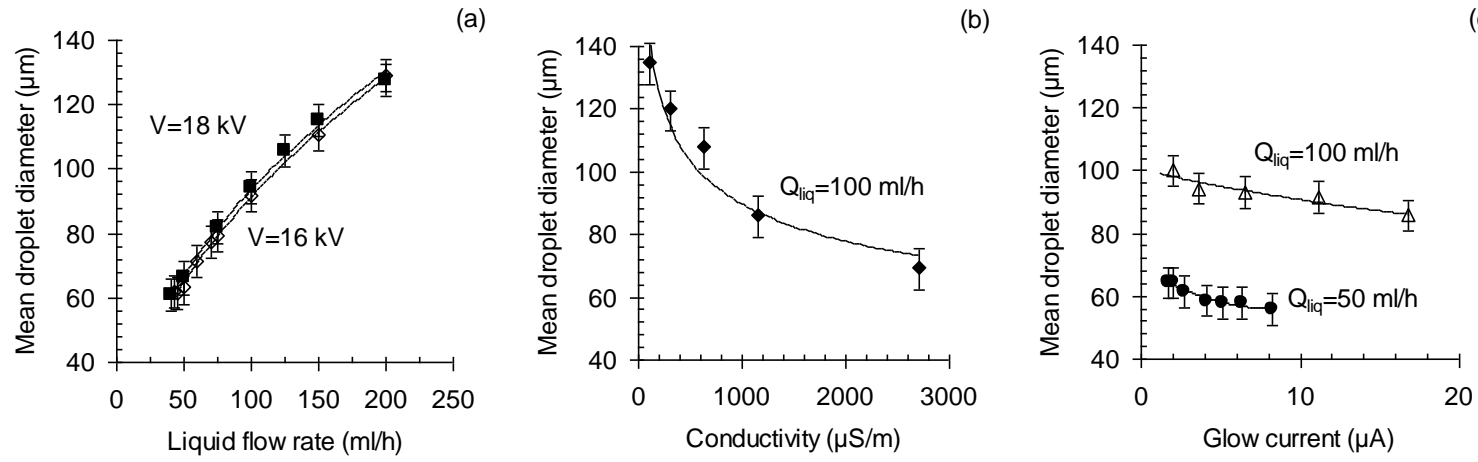

Fig. 10 Influence of (a) liquid flow rate $(\lambda=100 \mu \mathrm{S} / \mathrm{m})$; (b) conductivity ; (c) glow current $(\lambda=100 \mu \mathrm{S} / \mathrm{m})$ on the droplets diameter (Nozzle-to-plane configuration, $\mathrm{d}_{\text {gap }}=4 \mathrm{~cm}, \mathrm{D}_{\text {out }}=0.5 \mathrm{~mm}$ )

The increase of the conductivity and of the glow current (i.e. the increase of the electric field at the liquid surface) leads to a decrease of droplet diameter : indeed, in order to balance the increase of electrostatic pressure, the capillary pressure increases inducing a decrease of cone volume and of liquid jet diameter with fragmentation in smaller droplets. Nevertheless, the variation of droplet diameter with the glow current does not exceed more than $15 \%$ in relation with a small increase of the surface electric field related to the increase of the glow current and gaseous ions densities. This is noticeable because of the larger voltage variation (from 18 to $28 \mathrm{kV}$, corresponding to $64 \%$ of voltage variation) promoting the mode of EHDA stabilised by a continuous glow discharge. This is a consequence of the positive gaseous space charge produced close to the liquid surface by the continuous glow and which retrocontrols the field at the liquid surface and limits its increase with the voltage.

At least, the EHDA mode stabilised by a glow discharge enables to extend the range of liquid flow rate (from 35 to $200 \mathrm{ml} / \mathrm{h}$ ) and thus to extend the range of diameter and charge of water droplets that can be so-produced in this mode of EHDA stabilised by a glow, than those expected from the classical cone-jet mode without discharge (from 0.1 to $10 \mathrm{ml} / \mathrm{h}$ ). This implies larger water droplets that can be produced in this mode of EHDA (form 50 to 130 $\mu \mathrm{m})$ than those expected from Ganan-Calvo's laws for the cone-jet mode without electrical discharge (from 1 to $10 \mu \mathrm{m}$, proportional to $\mathrm{Q}_{\text {liq }}{ }^{0.3}$ and $\lambda_{\text {liq }}{ }^{-0.3}$ for polar liquid), as confirmed with this standard nozzle diameter in pressurised air, in $\mathrm{CO}_{2}$ [Tang and Gomez, 1994, 1995], or in particular wire plane configuration in air at atmospheric pressure [Borra et al., 1999].

\subsubsection{Spray current}

In the mode stabilised by a glow discharge, the total current is continuous and related to a component of gaseous ions created by a glow discharge $\left(\mathrm{I}_{\text {glow }}\right)$ produced in the cone peripheral and on the nozzle edges, and to a component of micrometer droplets $\left(\mathrm{I}_{\text {spray }}\right)$ :

$$
I_{\text {tot }}=I_{\text {glow }}+I_{\text {spray }}
$$

To define the evolution of the spray current as a function of experimental parameters, we must separate these two current components. A first ring at the ground potential is positioned a few millimetres from the nozzle tip. This electrode configuration allows to satisfy both 
conditions on EHD equilibrium and on glow discharge regime and to differentiate the current components without perturbing the jet fragmentation (production of droplets under the ring), as confirmed by droplet size measurement in both configurations. The positive charge density (created by strongly charged droplets under the ring) creates a space charge field which induces electrostatic repulsions between droplets : a part of the total amount of droplets flows under this first ring (see Fig. 11). Thus a second grounded ring is positioned under the first (nozzle-ring1-ring2-to-plane configuration), in order to collect the ions on the first ring and the droplets under the second ring and on the grounded plane. Experiments have been conducted with different positions of the rings along the symmetry axis of the system $(\mathrm{z}$ : axial coordinate) to define adequate position of the rings to separate the two current components.

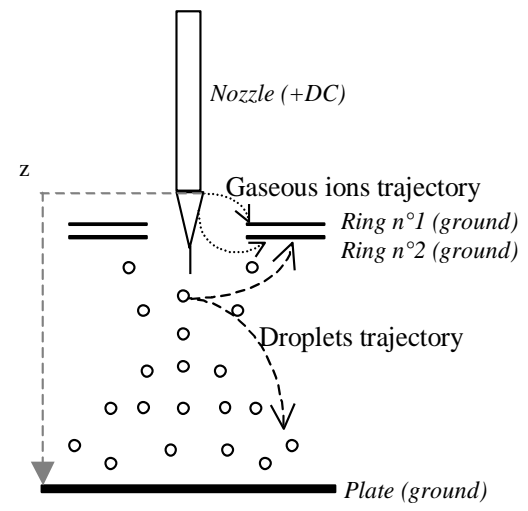

Fig. 11 Charged species trajectory (positive droplets and positive gaseous ions)

From measurements (see Fig. 12), an empirical law has been established to describe the influence of experimental parameters (liquid flow rate, conductivity and voltage) related to glow discharge current on the spray current related to mean droplet charge. This empirical law in the mode stabilised by a glow discharge has been expressed as follow :

$$
I_{\text {spray }} \sim Q_{\text {liq }}^{0.2} I_{\text {glow }}^{0.1} \lambda_{\text {liq }}^{0.2}
$$

The spray current increases with liquid flow rate as in the standard cone-jet mode without electrical discharge (proportional to $\mathrm{Q}_{\mathrm{liq}}{ }^{0.5}$ and $\lambda_{\text {liq }}{ }^{0.5}$ ). When the liquid flow rate increases, the electric charge per droplet increases, inducing an increase of the spray current $\left(I_{\text {spray }}=q_{\text {droplet }} v_{\text {droplets }}\right.$ ). The increase of the conductivity leads to an increase of the electric charge per droplet and of the spray current.
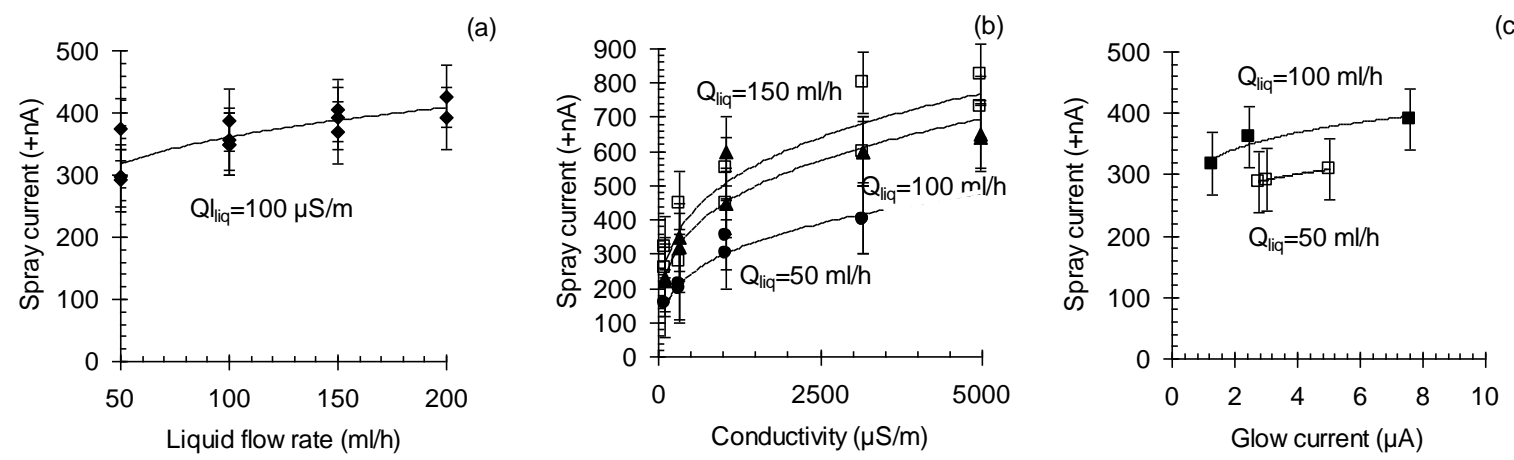

Fig. 12 Influence of (a) liquid flow rate $(\lambda=100 \mu \mathrm{S} / \mathrm{m})$, (b) conductivity, (c) glow current $(\lambda=100 \mu \mathrm{S} / \mathrm{m})$ on the spray current in the mode stabilised by a glow discharge

(Nozzle-ring1-ring2-plane configuration, $\mathrm{d}_{\mathrm{gap}}=4 \mathrm{~cm}, \mathrm{D}_{\text {out }}=0.5 \mathrm{~mm}$ ) 
The glow discharge enables to extend the range of liquid flow rate and of conductivity required for the EHDA in the mode stabilised by a glow discharge. This implies that higher droplet charge can be produced in this mode of EHDA stabilised by a glow discharge than those expected from Ganan-Calvo's laws for the standard cone-jet mode without electrical discharge. This higher spray currents and corresponding charge per droplet (ex : $\mathrm{Q}_{\text {liq }}=100 \mathrm{ml} / \mathrm{h}, \lambda=100 \mu \mathrm{S} / \mathrm{m}, \mathrm{q}_{\text {droplet }}=4.10^{-12} \mathrm{C}$ ), confirms the interest of this mode of EHDA stabilised by a glow discharge to produce highly charges water droplets for electrostatic applications (neutralisation or coagulation).

\section{CONCLUSIONS}

This paper deals with the production of unimodal charged water droplets by EHDA modes coexisting with electrical discharges, in air at atmospheric pressure. Photographs, current and size distributions measurements enable us to differentiate stable from unstable modes of EHDA related to electrical discharges phenomena.

This paper shows that the temporal variation of the electric field at liquid surface, which is defined by the electrical discharge regime, induces the EHDA modes of water : a strong impulse current (streamer regime) induces a transient variation of the electric field at the liquid surface, which disturbs the EHDA equilibrium, inducing the unstable mode of EHDA, whereas a continuous current (glow regime) promotes a stable mode of EHDA.

To promote the continuous glow discharge regime, leading to the mode of EHDA stabilised by the glow discharge, it is necessary to satisfy two conditions, the first one about the electric field normal to the liquid surface $\left(E_{n}\right)$ required to reach EHD equilibrium for the formation of the liquid cone and jet (condition similar to EHDA in standard cone-jet mode without electrical discharge) and the second about the electric field in the gas ( $\left.E_{\text {gas }}\right)$ to induce a continuous glow discharge regime.

This correlation is then confirmed by playing with experimental $\left(\mathrm{V}, \mathrm{Q}_{\text {liq }}\right)$ and regulation $\left(D_{\text {nozzle }}, \lambda\right)$ parameters to control the fields $\left(E_{n}\right.$ and $\left.E_{\text {gas }}\right)$ so as to promote the continuous glow discharge regime, leading to the mode of EHDA stabilised by the glow discharge. The operating ranges of this stable mode are defined for water according to conductivity, liquid flow rate, voltage and nozzle diameter.

Empirical laws are given to define droplets properties (droplets diameter and spray current) according to liquid flow rate, conductivity and glow current.

This study presents a new production mode of droplets by EHDA stabilised by glow discharge in air at atmospheric pressure, which allows to extend the ranges of mean diameter and electric charge than those expected from the standard cone-jet mode without discharge. Indeed, the EHDA of water in the mode stabilised by a glow discharge on larger voltage range (from 18 to $28 \mathrm{kV}$ ) and for higher liquid flow rate (from 35 to $200 \mathrm{ml} / \mathrm{h}$ ) than the standard cone-jet mode of EHDA without electrical discharges (a few $\mathrm{kV}$ from 0.1 to 10 $\mathrm{ml} / \mathrm{h}$ ). At this point, one has to keep in mind that the standard cone-jet mode of water without electrical discharge has only been observed with this standard nozzle diameter in pressurised air, in $\mathrm{CO}_{2}$ [Tang and Gomez, 1994, 1995], or in particular wire plane configuration in air at atmospheric pressure [Borra et $a l ., 1999]$.

Finally, higher spray currents and corresponding charge per droplet (ex: $\mathrm{Q}_{\text {liq }}=100 \mathrm{ml} / \mathrm{h}, \lambda=100 \mu \mathrm{S} / \mathrm{m}, \mathrm{q}_{\text {droplet }}=4.10^{-12} \mathrm{C}$ ), confirms the interest of this mode of EHDA stabilised by a glow discharge to produce highly charged water droplets for electrostatic applications of these water sprays (neutralisation, coagulation or deposition for filtration, humidifying, anti-dust dispersion systems).

Acknowledgments- We would like to acknowledge (i) CNRS who allowed us to file a patent, and to achieve a study of valorisation, (ii) IRSN of Saclay for their critical initial support in 
experimental and measurements facilities and (iii) EDF, as well as ECODEV-ADEME taking part of an ARC from CNRS for their financial support of this study.

\section{REFERENCES}

Bailey A.G. (1988) Electrostatic Spraying of Liquids, Research Studies Press LTD, Taunton, Somerset, England, John Wiley \& Sons INC., New York, Chichester, Toronto, Brisbane, Singapore.

Borra J-P., Hartmann R., Marijnissen J., Scarlett B. (1996) Destabilisation of sprays in the cone-jet mode by electrical discharges on the jet, Journal Aerosol Science, Vol.27, Suppl.1, pp.S203-S204.

Borra J-P., Tombette Y., Ehouarn P. (1999) Influence of electric field profile and polarity on the mode of EHDA related to electrical discharge regimes, Journal Aerosol Science, Vol.30, $\mathbf{N}^{\circ}$ 7, pp.913-925.

Burayev T.K., Vereshchagin I.P. (1972) Physical Processes during electrostatic atomization of liquids, Fluid Mechanics, Soviet Research, Vol.1, N², pp.56-66.

Cloupeau M., Prunet-Foch B. (1989) Electrostatic spraying of liquids in cone-jet mode, Journal of Electrostatics, Vol.22, pp.135-159.

Cloupeau M., Prunet-Foch B. (1990) Electrostatic spraying of liquids : Main functioning modes, Journal of Electrostatics, Vol.25, pp.165-184.

Cloupeau M. (1994) Recipes for use of EHD spraying in cone-jet mode and notes on Corona discharge effects, Journal Aerosol Science, Vol.25, Nº, pp.1143-1157.

Ehouarn P. (2001) Pulvérisation ElectroHydroDynamique de liquide stabilisée par décharges électriques pour le traitement d'effluents particulaires, Ph.D, Université Paris XI, France.

Fernandez de la Mora J., Loscertales I.G. (1994) The current emitted by highly conducting Taylor cones, J. Fluid. Mech., Vol.260, pp.155-184.

Grace J.M., Marijnissen J.C.M. (1994) A review of liquid atomization by electrical means, Journal Aerosol Science, Vol.25, $\mathbf{N}^{\circ} \mathbf{6}$, pp.1005-1019.

Ganan-Calvo A.M., Davila J., Barrero A. (1997) Current and droplet size in the electrospraying of liquids. Scaling Laws, Journal Aerosol Science, Vol.28, N², pp.249-275.

Hartman R.P.A. (1998) Electrohydrodynamic atomization in the cone-jet mode. From physical modelling to powder production, Ph.D, University of Delft, Pays-Bas.

Hartmann G., Goldman A., Buchet G., Zeitoun A. (1963) Contribution à l'étude de la décharge prédisruptive entre pointe et plan, Conférence Internationale sur les Phénomènes d'Ionisation dans les Gaz, Paris, Vol.2, pp.301-303.

Hayati I., Bailey A.I., Tadros TH.F. (1987) Investigations into the mechanisms of electrohydrodynamic spraying of liquids, Journal of Colloid and Interface Science, Vol.117, N¹, pp.205-221.

Jaworek A., Krupa A. (1997) Studies of the corona discharge in ehd spraying, Journal of Electrostatics, Vol.40 and 41, pp.173-178.

Lopez-Herrera J.M., Loscertales I.G., Marquez M., Barrero A. (2002) Steady cone-jet electrospraying of water in air at atmospheric pressure, $6^{\text {th }}$ International Aerosol Conference, 8-13 September, Taiwan, Taipei.

Michelson D. (1990) Electrostatic Atomization, Adam Hilger, Bristol and New York.

Meek J.M. (1940) Phys. Rev., Vol.57, pp.722-728.

Nasser E. (1971) Fundamentals of Gaseous Ionization and Plasma Electronics, Wiley-Interscience, New York, United Stated.

Raether H. (1941) Zeit. Phys., Vol.117, pp.394-524.

Smith D.P.H. (1986) The Electrohydrodynamic atomization of liquids, IEEE Transactions on industry applications, Vol.IA-22, $\mathbf{N}^{\circ} 3$.

Tang K., Gomez A. (1994) Generation by electrospray of monodisperse water droplets for targeted drug delivery by inhalation, Journal Aerosol Science, Vol.25, N6, pp.1237-1249.

Tang K., Gomez A. (1995) Generation of monodisperse water droplets from electrosprays in a corona-assisted cone-jet mode, Journal of Colloid and Interface Science, Vol.175, pp.326-332.

Taylor G. (1964) Disintegration of water drops in an electric field, Proceeding of the Royal Society of London, Mathematical and Physical Sci., Vol.280, pp.383-397.

Towsend J.S. (1914) Electricity in Gases, Oxford University Press.

Vonnegut B., Neubauer R.L. (1952) Production of monodisperse liquid particles by electrical atomization, Journal Colloid Science, Vol.7, pp.616-622.

Zeleny J. (1915) On the conditions of instability of electrified drops, with applications to the electrical discharge from liquid points, Proceedings of the Cambridge philosophical society, Vol.18, pp.71-83. 